\title{
Water source as a Helicobacter pylori transmission route: a 3-year follow-up study of Japanese children living in a unique district
}

Helicobacter pylori is associated with the pathogenesis of chronic gastritis, peptic ulcer disease and gastric cancer (MatysiakBudnik \& Megraud, 2006). It is thought that the acquisition of $H$. pylori infection occurs mainly during childhood

(Sherman, 2004). Although an

intrafamilial route has been suggested (Kivi \& Tindberg, 2006), the major routes of transmission of $H$. pylori are poorly understood. There have been cases reported in which the intrafamilial route does not appear to apply. In 2002, we investigated $H$. pylori prevalence in 224 children (age range 0-6 years) in three districts in Miyagi prefecture, Japan (Fujimura et al., 2004). The H. pylori prevalence rate in the children studied was $0 \%$ in district C. H. pylori prevalence rates in districts A and B were approximately equal to those in other reports from Japan (Kato et al., 2003a). However, there were no reports of $0 \%$ prevalence rates such as found in district C. Therefore, we examined $H$. pylori prevalence 3 years later to determine whether the prevalence rate in the children of district $\mathrm{C}$ had changed.

From among the 51 children (age 3-5 years) investigated in district $C$ in 2002, 40 children (age 6-8 years in the follow-up study) in 37 households, from whom informed consent was obtained, were re-examined in this study. H. pylori status was estimated using a stool antigen test (Premier Platinum HpSA; Meridian Bioscience) (Kato et al., 2003b). According to the manufacturer's instructions, the results were divided into three groups for $H$. pylori infection: positive $\left(\mathrm{OD}_{450 / 630} \geqslant 0.120\right)$; negative $(<0.100)$; and indeterminate $(0.100-0.199)$. Further, we studied $H$. pylori prevalence among the family members (the parents and siblings) who live together with the subject children. Informed consent was obtained from 24 of the 37 original households $(64.9 \%)$.

However, because agreement for obtaining stool samples was not obtained, the $H$. pylori status of the parents and siblings was assessed using a commercial ELISA kit
(URINELISA H. pylori antibody; Otsuka Pharmaceutical) to detect anti-H. pylori IgG antibodies (Miwa et al., 1999).

The survey collected information regarding childcare and the living environment and included birthplace, feeding methods in infancy and the source of the household water.

All 40 children who were uninfected with $H$. pylori in 2002 remained $H$. pylori-negative at the 3-year follow-up. The H. pylori prevalence of their parents (mean age 38.9 years; range $27-51$ years) was $35.4 \%$ (17/ 48). Among the 48 parents in 24 households, the prevalence rates of $H$. pylori for natives of district $\mathrm{C}$ and for people who had moved into the area from the outside were $37.5 \%$ $(12 / 32)$ and $31.3 \%(5 / 16)$, respectively (Table 1). The mean age of the native parents who were infected with $H$. pylori was 40.8 years with a range of $35-51$ years. Of the 24 households, at least one parent was infected in 14. Among these 14 households, the rates of infection of both parents, of the fathers, and of the mothers were $21.4 \%$ $(3 / 14), 42.9 \%(6 / 14)$ and $35.7 \%(5 / 14)$, respectively. There were 14 households in which the subject had siblings; except for one family, none of the siblings were infected with $H$. pylori (Table 1 ). In the sole exception, the parents and both siblings were infected with $H$. pylori. These two siblings had not, as infants, been fed prechewed food by infected parents. However, another subject who was fed pre-chewed food by an infected mother was H. pylorinegative in a different household. There was no relationship between $H$. pylori infection and whether or not the subjects had received pre-chewed food during their infancy.

In a Japanese report, it has been shown that the infection rate of $H$. pylori was $8-10 \%$ at less than 10 years of age and was about $35 \%$ at 30-40 years (Asaka et al., 1992). The $H$. pylori prevalence rate in parents in district $\mathrm{C}$ is almost in accord with that in another Japanese report (Kato et al., 2003a). Although it is known that $H$. pylori is acquired mainly during childhood, these results suggests that the living environment in district $\mathrm{C}$ where the parents spent their childhood 30-35 years ago was equivalent to that in other districts in Japan. District C with a population of 9000 is located in a rural area at the foot of a mountain range and is 10-20 km away from districts A and B. There are many reports pointing to drinking water as a transmission source for $H$. pylori (Bellack et al., 2006; Fujimura et al., 2004; Kikuchi \& Dore, 2005). There are some reports that $H$. pylori DNA was detected in well water in Japan (Horiuchi et al., 2001). In the three districts (A, B and C), all households used well water until 1975 , and city water then became available. The source of water in districts $\mathrm{A}$ and $\mathrm{B}$ has been river water since 1975. However, in district C, groundwater from a layer deeper than that of general groundwater has been used as the water source. In a previous study, water samples were taken from three points (upper, middle and downstream reaches) along four rivers in the Tohoku region of Japan. We reported that $H$. pylori DNA was not detected in water samples from the upper reaches in the high mountains outside of the human biosphere but it was detected in the middle or lower reaches (Fujimura et al., 2004). In the current study, the $H$. pylori-specific ureA gene was not detected in the groundwater of district $\mathrm{C}$ (data not shown). Since we failed to culture $H$. pylori from tap water and well water, the use of tap water derived from a water source which is not contaminated with $H$. pylori may account for the fact that no children living in district $\mathrm{C}$ were infected with $H$. pylori. In addition, the questionnaire results concerning feeding style in infancy, particularly feeding the child pre-chewed food, suggest that the possibility of $H$. pylori spreading via the intrafamilial route is low in this area. In Japan, the primary source of citysupplied water is rivers. There are extremely few cases like that of district $C$ where spring water or groundwater from the high mountains is used as a source. Though the transmission source of $H$. pylori has not been 
Table 1. Relationship between $H$. pylori status and the birthplace of parents and siblings of subject cases

\begin{tabular}{|c|c|c|c|c|}
\hline Birthplace & H. pylori status & Father & Mother & Sibling ${ }^{\star}$ \\
\hline \multirow[t]{3}{*}{ District C } & Positive & 8 & 4 & $2 \dagger$ \\
\hline & Negative & 12 & 8 & 16 \\
\hline & Total & 20 & 12 & 18 \\
\hline \multirow[t]{3}{*}{ Other districts } & Positive & 1 & 4 & - \\
\hline & Negative & 3 & 8 & - \\
\hline & Total & 4 & 12 & - \\
\hline
\end{tabular}

*-, None fitted the criteria.

$\dagger$ Two siblings and parents in only one family were infected with H. pylori.

clarified, $H$. pylori infection in children may be suppressed if drinking water is not of river water origin.

\section{Shigeru Fujimura, ${ }^{1,2}$ Seiichi Kato ${ }^{3}$ and Akira Watanabe ${ }^{1}$}

${ }^{1}$ Research Division for Development of Anti-Infective Agents, Institute of Development, Aging and Cancer, Tohoku University, Sendai, Japan

${ }^{2}$ Department of Microbiology, Miyagi University, Miyagi prefecture, Japan

${ }^{3}$ Department of Pediatrics, Tohoku University School of Medicine, Sendai, Japan

Correspondence: Shigeru Fujimura (fujimo@idac.tohoku.ac.jp)

Asaka, M., Kimura, T., Kudo, M., Takeda, H., Mitani, S., Miyazaki, T., Miki, K. \& Graham, D. Y.
(1992). Relationship of Helicobacter pylori to serum pepsinogens in an asymptomatic Japanese population. Gastroenterology 102, 760-766.

Bellack, N. R., Koehoorn, M. W., MacNab, Y. C. \& Morshed, M. G. (2006). A conceptual model of water's role as a reservoir in Helicobacter pylori transmission: a review of the evidence. Epidemiol Infect 134, 439-449.

Fujimura, S., Kato, S. \& Kawamura, T. (2004). Helicobacter pylori in Japanese river water and its prevalence in Japanese children. Lett Appl Microbiol 38, 517-521.

Horiuchi, T., Ohkusa, T., Watanabe, M., Kobayashi, D., Miwa, H. \& Eishi, Y. (2001). Helicobacter pylori DNA in drinking water in Japan. Microbiol Immunol 45, 515-519.

Kato, S., Okamoto, H., Nishino, Y., Oyake, Y., Nakazato, Y., Okuda, M., Fujisawa, T., linuma, K. \& Blaser, M. J. (2003a). Helicobacter pylori and TT virus prevalence in Japanese children. J Gastroenterol 38, 1126-1130.

Kato, S., Ozawa, K., Okuda, M., Fujisawa, T., Kagimoto, S., Konno, M., Maisawa, S. \& linuma, K. (2003b). Accuracy of the stool antigen test for the diagnosis of childhood Helicobacter pylori infection: a multicenter Japanese study. Am J Gastroenterol 98,

296-300.

Kikuchi, S. \& Dore, M. P. (2005). Epidemiology of Helicobacter pylori infection. Helicobacter 10 (Suppl. 1), 1-4.

Kivi, M. \& Tindberg, Y. (2006). Helicobacter pylori occurrence and transmission: a family affair? Scand J Infect Dis 38, 407-417.

Matysiak-Budnik, T. \& Megraud, F. (2006). Helicobacter pylori infection and gastric cancer. Eur J Cancer 42, 708-716.

Miwa, H., Hirose, M., Kikuchi, S., Terai, T., Iwazaki, R., Kobayashi, O., Takei, Y., Ogihara, T. \& Sato, N. (1999). How useful is the detection kit for antibody to Helicobacter pylori in urine (URINELISA) in clinical practice? Am J Gastroenterol 94, 3460-3463.

Sherman, P. M. (2004). Appropriate strategies for testing and treating Helicobacter pylori in children: when and how? Am J Med 117 (Suppl. 5A), 30S-35S. 